\title{
Studies on preparation of matrine solid dispersion
}

\section{sustained-release tablets}

\author{
Li Zao-hui ${ }^{1, a}$ Wang Jiao $^{2}$ \\ ${ }^{1}$ Jilin agricultural science and technology college Jilin 132101 \\ ${ }^{2}$ Jilin agricultural science and technology college Jilin 132101 \\ a315203552@qq.com
}

Project: Jilin Agricultural Science and Technology College Youth Fund Project (119012014017)

Keywords: matrine; solid dispersion; sustained-release tablets ; release rate

Abstract: Objective: Matrine was made into solid dispersion sustained-release tablets. Methods: Ingredients are screened by single factor test and orthogonal,forming ingredient of sustained-release tablets was determined by appearance,formability, dissolution and $d$ hardness of tablets. Results: The result showed that the optimum formulation was composed of HPMC 12g, lactose 9.5,3\%PVP 8ml,magnesium stearate $0.5 \mathrm{~g}$. Conclusion: Matrine solid dispersion sustained-release tablets meets the requirement of meets the requirements of suspension preparation with pharmacopoeia with stable quality.

Sophora flavescens which contains a variety of alkaloids is the dry roots of legumes, whose main component is matrine extracted with ethanol organic solvent. Preventing liver injury,anti-hepatic fibrosis,antitumor,cardiovascular are the main pharmacological effects of matrine.the traditional oral dosage form of matrine absorption effect is relatively poor. preparation of matrine solid dispersion sustained-release tablets can improve drug stability,increase the solubility and reduce the number of medication to a stable plasma concentration and treatment effect which avoid the phenomenon of peak and valley because of timing positioning drug release.. $[1-5]$

1 Instruments and materials

PEG6000,HPMC,MC,EC,PVP,CMC-Na,MCC,dextrin,lactose,magnesium stearate ,talc (Tianjin Damao Chemical Reagent Factory) ;Other drugs and reagents are of analytical grade. YPD-300D tablet hardness tester, CJY-300D tablet friability tester, RCZ-8 drug dissolution tester, TDP-1.5 single punch tablet machine (Ohaus); GZX-914MB electric thermostat oven (Changsha City in the South Pharmaceutical Machinery Factory)

2 Experimental method

2.1 Preparation of matrine solid dispersion and standard curve

Matrine monomer is dissolved in the proper amount of anhydrous ethanol. PEG6000 water bath heat and melt in constant temperature $\left(80{ }^{\circ} \mathrm{C}\right)$.A mixture of matrine monomer and PEG6000(1:9) magnetic stirring (100 r/ $\mathrm{min}) 3 \mathrm{~min}$ to achieve uniformity and continue stirring to solvent evaporated. Cooled at $-20{ }^{\circ} \mathrm{C}$ for a predetermined time, the finished product are stored in the dryer for $24 \mathrm{~h}$, porphyrize and sieve( 80 meshes). 
Preparation of standard curve: the standard curve equation with the absorbance A and matrine standard concentration $\mathrm{C}(\mathrm{ug} / \mathrm{mL}$ ) is the ordinate and abscissa in the linear range of $5 \sim 25 \mathrm{ug} \bullet \mathrm{mL}-1$.

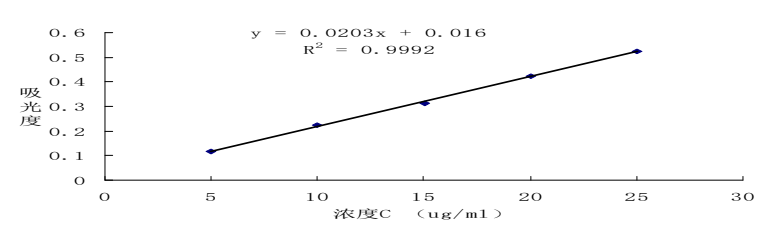

Figure 1: standard curve

\subsection{Screening for the specie and dosage of Skeleton material ${ }^{[6]}$}

The recipe that are the matrine solid dispersion( $30 \mathrm{~g})$, lactose $(9.5 \mathrm{~g}), 3 \% \mathrm{PVP}(7 \mathrm{ml})$, magnesium stearate $(0.5 \mathrm{~g}), \mathrm{HPMC}(12 \mathrm{~g})$ or $\mathrm{MC}(12 \mathrm{~g})$ or $\mathrm{EC}(12 \mathrm{~g})$ are respectively made. HPMC is the skeleton material by release rate as evaluation indicator.

The recipe that are matrine solid dispersion( $30 \mathrm{~g})$, lactose $(9.5 \mathrm{~g}), 3 \% \mathrm{PVP}(7 \mathrm{ml})$, magnesium stearate $(0.5 \mathrm{~g})$, HPMC $(12 \mathrm{~g}$ or $13 \mathrm{~g}$ or $14 \mathrm{~g}$ or $15 \mathrm{~g}$ or $16 \mathrm{~g})$ are respectively made. The dosage of HPMC is $12 \mathrm{~g}$ by release rate as evaluation indicator.

Table 1: screening for the specie skeleton materials

\begin{tabular}{|c|c|c|c|c|c|}
\hline \multicolumn{3}{|c|}{ skeleton materials } & \multicolumn{3}{|c|}{$(12 \mathrm{~h})$ release rateQ $(\%)$} \\
\hline \multicolumn{3}{|c|}{ HPMC } & \multicolumn{3}{|c|}{89.4} \\
\hline \multicolumn{3}{|c|}{$\mathrm{MC}$} & \multicolumn{3}{|c|}{82.2} \\
\hline \multicolumn{3}{|c|}{$\mathrm{EC}$} & \multicolumn{3}{|c|}{84.6} \\
\hline \multicolumn{6}{|c|}{ Table 2: screening the dosage of skeleton materials } \\
\hline $\begin{array}{l}\text { evaluation } \\
\text { indicator }\end{array}$ & $12 \mathrm{~g}$ & $13 \mathrm{~g}$ & $14 \mathrm{~g}$ & $15 \mathrm{~g}$ & $16 \mathrm{~g}$ \\
\hline $\begin{array}{l}12 \mathrm{~h} \text { release } \\
\text { rate }(\%)\end{array}$ & 93.40 & 86.20 & 82.10 & 81.50 & 89.80 \\
\hline
\end{tabular}

2.3 Screening for the specie and dosage of lubricant ${ }^{[7]}$

The recipe that are the matrine solid dispersion( $30 \mathrm{~g})$, lactose $(9.5 \mathrm{~g}), \mathrm{HPMC}$ $(12 \mathrm{~g}), 3 \% \mathrm{PVP}(7 \mathrm{ml})$, magnesium stearate $(0.5 \mathrm{~g})$ o rtalc $(0.5 \mathrm{~g})$ or micro-silica $(0.5 \mathrm{~g})$ are respectively made. Magnesium stearate is lubricant by appearance and formability as evaluation indicator.

The recipe that are matrine solid dispersion $(30 \mathrm{~g})$, lactose $(9.5 \mathrm{~g})$, HPMC $(12 \mathrm{~g}), 3 \% \mathrm{PVP}(7 \mathrm{ml})$, magnesium stearate $(0.4 \mathrm{~g}$ or $0.5 \mathrm{~g}$ or $0.6 \mathrm{~g})$ are respectively made. The dosage of magnesium stearate is $0.5 \mathrm{~g}$ by appearance and formability as evaluation indicator.

2.4 Screening for the specie and dosage of filler ${ }^{[8]}$

The recipe that are the matrine solid dispersion(30g), HPMC $(12 \mathrm{~g}), 3 \% \mathrm{PVP}(7 \mathrm{ml})$, lactose $(9.5 \mathrm{~g}), \mathrm{MCC}(9.5 \mathrm{~g})$ or dextrin( $(9.5 \mathrm{~g})$ or magnesium stearate $(0.5 \mathrm{~g})$ are respectivey made. Lactoseis filler by release rate as evaluation indicator.

The recipe that are matrine solid dispersion( $30 \mathrm{~g})$, lactose $(9 \mathrm{~g}$ or $9.5 \mathrm{~g}$ or $10 \mathrm{~g})$, HPMC $(12 \mathrm{~g}), 3 \% \mathrm{PVP}(7 \mathrm{ml})$, magnesium stearate $(0.5 \mathrm{~g})$ are respectively made. The 
dosage of lactose is $9.5 \mathrm{~g}$ by release rate as evaluation indicator.

Table 3: screening for the specie of filler

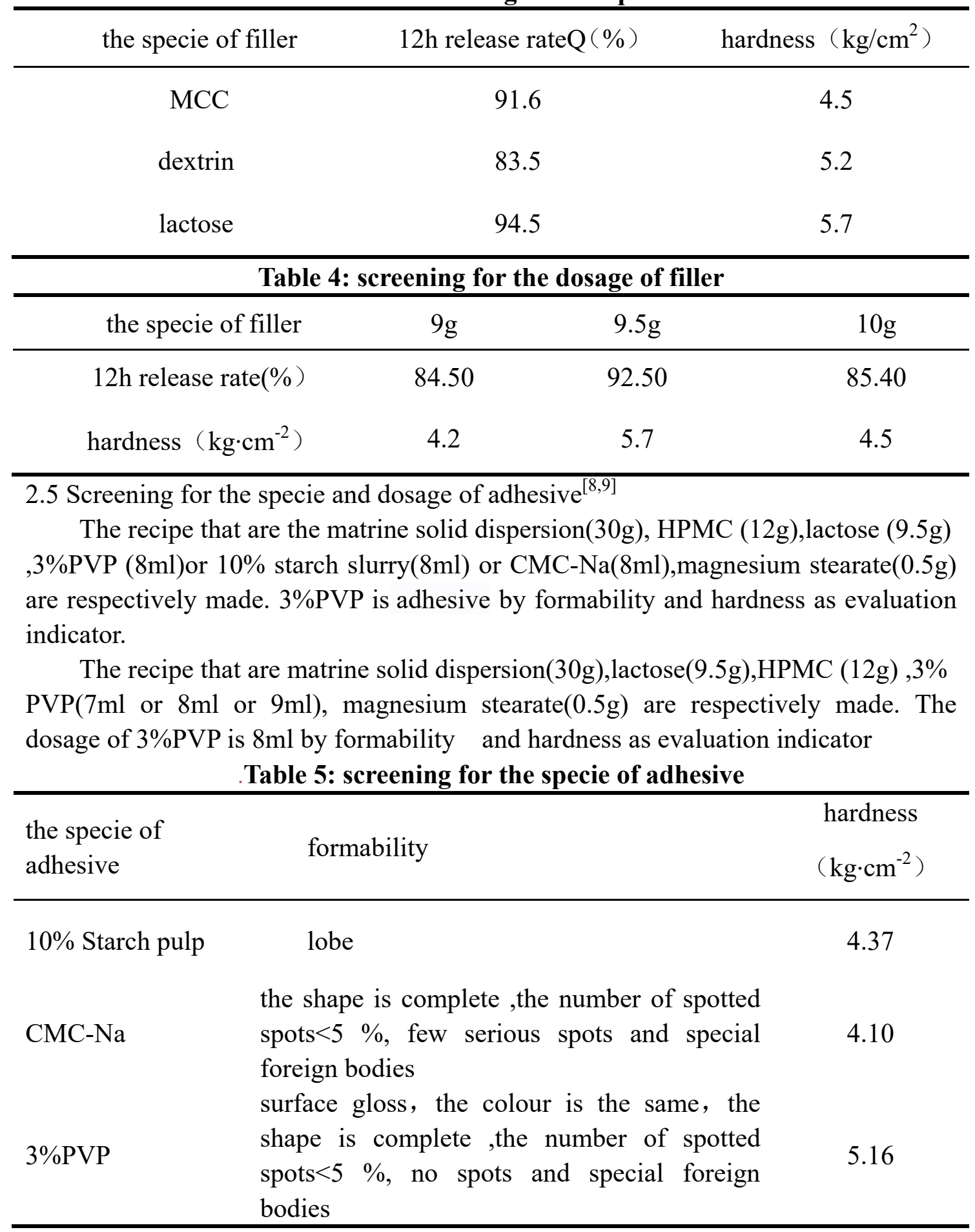


Table 6: screening for the dosage of adhesive

\begin{tabular}{ccc}
\hline the dosage of adhesive & formability & $\begin{array}{c}\text { hardness } \\
\left(\mathrm{kg} \cdot \mathrm{cm}^{-2}\right)\end{array}$ \\
\hline $7 \mathrm{ml}$ & $\begin{array}{c}\text { lobe, surface gloss } \\
\text { the shape is complete, no spots } \\
\text { and special foreign bodies }\end{array}$ & 4.67 \\
$8 \mathrm{ml}$ & sticking and picking & 4.51 \\
$9 \mathrm{ml}$ & 5.25 \\
\hline
\end{tabular}

2.6 Screening for the proportion of drugs and excipient

The recipe that the proportion of the matrine solid dispersion and excipient is $1: 1$ or $2: 3$ or $1: 2$ or $1: 3$ are respectively made. The proportion of the matrine solid dispersion and excipient is $1: 1$ by release rate as evaluation indicator.

Table 7: the proportion of drugs and excipient

\begin{tabular}{ccccc}
\hline $\begin{array}{c}\text { The proportion of } \\
\text { drugs and excipient }\end{array}$ & $1: 1$ & $2: 3$ & $1: 2$ & $1: 3$ \\
\hline $\begin{array}{c}12 \mathrm{~h} \text { release } \\
\text { rate }(\%)\end{array}$ & 94.62 & 86.47 & 82.36 & 82.17 \\
\hline
\end{tabular}

2.7 Orthogonal test method

After single factor study, the factors and levels of orthogonal test are determined. Through the orthogonal design scheme of $\mathrm{L}_{9}\left(3^{4}\right)$, screen the optimum dosage of the skeleton material, the lubricant, the filler and the adhesive by $12 \mathrm{~h}$ release rate as evaluation indicator.

Preparation of standard curve: the standard curve equation with the absorbance A and matrine standard concentration $\mathrm{C}(\mathrm{ug} / \mathrm{mL})$ is the ordinate and abscissa in the linear range of $5 \sim 25 \mathrm{ug} \bullet \mathrm{mL}-1$.

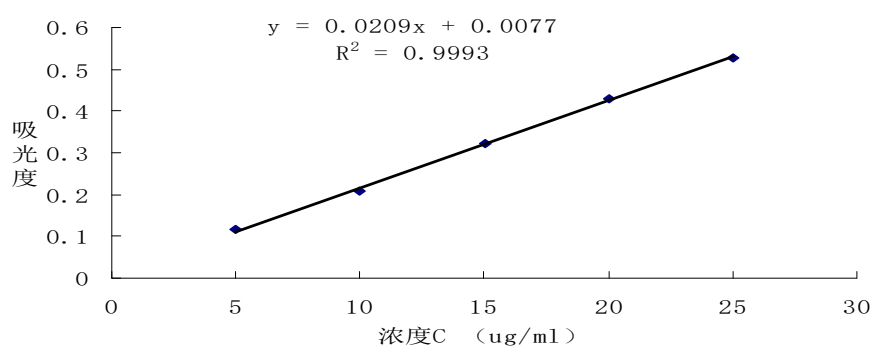

Figure 2: standard curve of orthogonal test 
Table 8: factor level charts

\begin{tabular}{|c|c|c|c|c|c|}
\hline \multirow{3}{*}{ 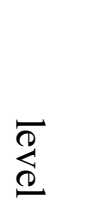 } & \multicolumn{5}{|c|}{ factor } \\
\hline & $\mathbf{A}$ & & B & $\mathbf{C}$ & D \\
\hline & HPMC $(g)$ & lactose & (g) & $3 \% \mathrm{PVP}(\mathrm{ml})$ & magnesium stearate $(\mathrm{g})$ \\
\hline 1 & 12 & & 9 & 6 & 0.4 \\
\hline 2 & 14 & & 9.5 & 7 & 0.5 \\
\hline 3 & 16 & & 10 & 8 & 0.6 \\
\hline
\end{tabular}

Table 9: orthogonal test results

\begin{tabular}{cccccc}
\hline $\begin{array}{c}\text { Test } \\
\text { number }\end{array}$ & $\begin{array}{c}\mathrm{A} \\
(\mathrm{HPMC} / \mathrm{mg})\end{array}$ & $\begin{array}{c}\mathrm{B} \\
(\mathrm{lactos} \\
\mathrm{e} / \mathrm{mg})\end{array}$ & $\begin{array}{c}\mathrm{C} \\
(3 \% \mathrm{PV} \\
\mathrm{P} / \mathrm{ml})\end{array}$ & $\begin{array}{c}\mathrm{D} \\
(\text { magnesium } \\
\text { stearate } / \mathrm{mg})\end{array}$ & $\begin{array}{c}\mathrm{Q}(\% \\
\text { ( })\end{array}$ \\
\hline 1 & 1 & 1 & 1 & 1 & 86.46 \\
2 & 1 & 2 & 2 & 2 & 94.03 \\
3 & 1 & 3 & 3 & 3 & 93.35 \\
4 & 2 & 1 & 2 & 3 & 79.35 \\
5 & 2 & 2 & 3 & 1 & 83.36 \\
6 & 2 & 3 & 1 & 2 & 75.85 \\
7 & 3 & 2 & 3 & 2 & 84.11 \\
8 & 3 & 3 & 2 & 3 & 76.32 \\
9 & 3 & 83.31 & 79.54 & 82.71 & \\
I & 91.28 & 84.57 & 83.90 & 84.66 & \\
II & 79.52 & 82.50 & 86.94 & 83.01 & \\
III & 79.58 & 2.07 & 7.40 & 1.95 & \\
R & 11.76 & 2.07 & 1 & 1 & 78.31 \\
\hline
\end{tabular}

Based on the orthogonal test results , the order of influence is $\mathrm{A}>\mathrm{C}>\mathrm{B}>\mathrm{D}$. The best combination of factors is $\mathrm{A}_{1} \mathrm{~B}_{2} \mathrm{C}_{3} \mathrm{D}_{2}$ in which the dosage of HPMC, lactose, $3 \% \mathrm{PVP}$ and magnesium stearate are respectively $12 \mathrm{~g}, 9.5 \mathrm{~g}, 8 \mathrm{ml}, 0.5 \mathrm{~g}$. 
Table 10: analysis of varia-nee

\begin{tabular}{cccccc}
\hline $\begin{array}{c}\text { The source } \\
\text { of cariance }\end{array}$ & $\begin{array}{c}\text { square of } \\
\text { deviance }\end{array}$ & $\begin{array}{c}\text { degree } \\
\text { of freedom }\end{array}$ & F ratio & $\begin{array}{c}\text { F } \\
\text { value }\end{array}$ & $\begin{array}{c}\text { signific } \\
\text { ant }\end{array}$ \\
\hline HPMC & 275.191 & 2 & $\begin{array}{l}42.25 \\
9\end{array}$ & 19.000 & $*$ \\
lactose & 6.512 & 2 & 1.000 & 19.000 & \\
3\%PVP & 82.924 & 2 & 12.73 & 19.000 & \\
$\begin{array}{c}\text { magnesium } \\
\text { stearate }\end{array}$ & 6.648 & 2 & 1.021 & 19.000 & \\
error & 6.51 & 2 & & & \\
\hline
\end{tabular}

The results of variance analysis show that the HPMC have significant effect on experimental results. The 3\% PVP, the lactose and the magnesium stearate have no significant effect .

\subsection{Verification test}

Accoding to results obtained by orthogonal test, three batches of matrine solid dispersion sustained release tablets are made and measure the release rate of this sustained release tablet to verify whether the excipient and preparation process is optimal.

Table11: verification test $(n=3)$

\begin{tabular}{cc}
\hline number & $(12 \mathrm{~h})$ \\
\hline 1 & release rate $(\%)$ \\
2 & 94.46 \\
3 & 94.23 \\
\hline
\end{tabular}

2.9 Quality inspection ${ }^{[10,11,12]}$

\subsubsection{Visual inspection}

Inspecting twenty pieces of matrine solid dispersion sustained release tablets showed surface gloss,complete, no spots and special foreign bodies which conform to the Chinese Pharmacopoeia.

2.9.2 Determination of tablet weight difference

According to $2015 \mathrm{ChP}$, weigh twenty pieces of matrine solid dispersion sustained release tablets and determine each weight and average weight.The result shows sample piece of weight differences are within limits.

\subsubsection{Hardness determination}

According to $2015 \mathrm{ChP}$,inspect the hardness of matrine solid dispersion sustained release tablets. The consequence showed average hardness of sustained release tablet is $5.16 \mathrm{~kg} / \mathrm{cm}^{2}$. 
Table12:the results of hardness test

\begin{tabular}{ccccccc}
\hline number & 1 & 2 & 3 & 4 & 5 & 6 \\
\hline $\begin{array}{l}\text { hardness }\left(\mathrm{kg} . \mathrm{cm}^{-2}\right) \\
\begin{array}{c}\text { Average hardness } \\
\text { (kg.cm-2) }\end{array}\end{array}$ & 5.72 & 5.35 & 4.79 & 4.82 & 5.33 & 4.94 \\
\hline
\end{tabular}

2.10.4 Drug release determination

Matrine standard substances $(10 \mathrm{mg})$ is set in $100 \mathrm{~mL}$ with anhydrous ethanol and amount $0.5 \mathrm{~mL} 、 1.0 \mathrm{~mL} 、 1.5 \mathrm{~mL} 、 2.0 \mathrm{~mL} 、 2.5 \mathrm{~mL}$ to $100 \mathrm{~mL}$. Matrine standard substances at concentration of $5.0 \mathrm{ug} / \mathrm{mL} 、 10.0 \mathrm{ug} / \mathrm{mL} 、 15.0 \mathrm{ug} / \mathrm{mL} 、 20.0 \mathrm{ug} / \mathrm{mL} 、 25.0 \mathrm{ug} / \mathrm{mL}$ determine absorbance at wave length of $620 \mathrm{~nm}$. The standard curve equation with the absorbance A and matrine standard concentration $\mathrm{C}(\mathrm{ug} / \mathrm{mL})$ is the ordinate.

The release behavior of sustained-release tabletis studied by cylindrical basket method. The release medium is $\mathrm{pH} 6.8 \mathrm{KH}_{2} \mathrm{PO}_{4}-\mathrm{NaOH}$, and temperature is $37 \pm 1{ }^{\circ} \mathrm{C}$, samples were obtained $4,6,8,10,12 \mathrm{~h}$ and quantitated at $620 \mathrm{~nm}$ by Ultraviolet spectrophotometer.

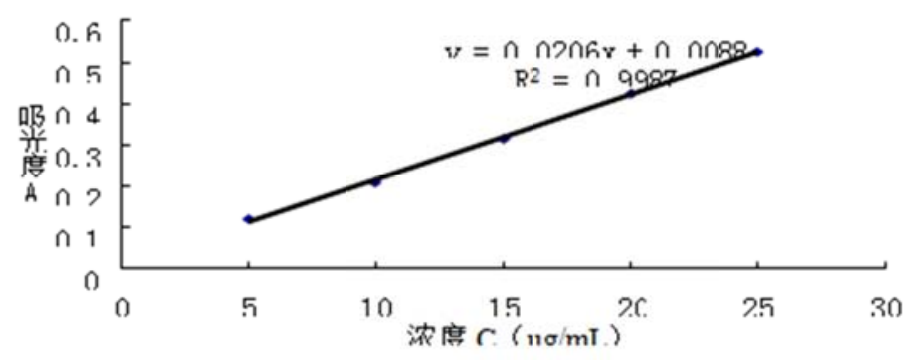

Figure 3: standard curve of quality inspection

Table13: Cumulative release (\%) Test results

\begin{tabular}{ccccrrrr}
\hline number & $\begin{array}{l}4 \mathrm{~h} \\
\text { rate Q }\end{array}(\%)$ & $\begin{array}{l}\text { release } \\
\text { rate Q }\end{array}(\%)$ & $\begin{array}{c}\text { release } \\
(\%)\end{array}$ & $\begin{array}{c}\text { release } \\
\text { rate Q }(\%)\end{array}$ & $\begin{array}{l}\text { 10hrelease } \\
\text { rate Q }(\%)\end{array}$ & $\begin{array}{c}\text { 12hrelease } \\
\text { rate Q }(\%)\end{array}$ \\
\hline 1 & 29.37 & 48.81 & 74.86 & 82.84 & 94.86 \\
2 & 28.95 & 49.24 & 75.42 & 88.62 & 95.42 \\
3 & 28.87 & 48.88 & 74.44 & 84.43 & 94.44 \\
\hline
\end{tabular}

2.10.5 Fragileness determination

According to $2015 \mathrm{ChP}$, inspect the fragileness of matrine solid dispersion sustained release tablets. The result shows every sample weight loss is $<1 \%$. 
Table 14: Fragile checklist

\begin{tabular}{cccc}
\hline number & 1 & 2 & 3 \\
\hline $\begin{array}{c}\text { Total weight of } \\
\text { sustained release } \\
\text { tablets before testing } \\
(\mathrm{g})\end{array}$ & 6.5834 & 6.5953 & 6.5446 \\
$\begin{array}{c}\text { Total weight of } \\
\text { sustained release } \\
\text { tablets after testing }(\mathrm{g})\end{array}$ & 6.5512 & 6.5559 & 6.5234 \\
$\begin{array}{c}\text { loss of weight }(\mathrm{g}) \\
\text { percentage of weight } \\
\text { loss }(\%)\end{array}$ & 0.0322 & 0.0394 & 0.0212 \\
\hline
\end{tabular}

\section{Summary}

From this study, the excipients and the best formula of the sustained-release tablets and other conditions were optimal selection by the single factor test, orthogonal test, validation test, and quality inspection.Matrine common tablets contain low total alkalinity, and is not easy to disperse and dissolution, low bioavailability, poor compliance to patients .Compared with the conventional preparation, the sustained-release preparation is easy to use, the frequency of drugs is small, plasma concentration is stable, no the "peak and valley" phenomenon and timing and positioning release. Adverse reactions are relatively reduced, and its great advantage is to meet the need for long-term use of drugs .

\section{References}

[1]Liu mei, Liu xueying \&Cheng Jianfeng. Progress in Pharmacology of Matrine [J]. Chinese Journal of Chinese Materia Medica, 2003,09: 11-14.

[2]Chen weiguang. Study on Progress of Matrine Pharmacological[J].Occupation And Health, 2002 , 02:14-15.

[3]Gong fengge. Research Progress of Controlled Release Tablets[J].TianJin Pharmacy,2010 (05):8-10.

[4]Lin hui. Development of Traditional Chinese Medicine Sustained - release Preparations [J].Strait Pharmaceutical Journal, 2002,05:114-117.

[5]Zhang xiudan, Li xianqing \&Liu lin. New Advances in Matrine Pharmacology and Preparations [J]. Archives of Traditional Chinese Medicine, 2006,11:2011-2013.

[6]Yao hui,Deng hongzhu \&Zhang jiping. Preparation of Ginkgo biloba sustained release tablets[J], Pharmacy Today,2009,(04):52-54.

[7]Shi lei,Fan Changchun. Preparation and in vitro release of simvastatin gelssu stained release tablets, China Medical Herald,2011.8(26):76-78.

[8]Jing qiufang,Ren fuzheng\&Shen yongjia. The preparation and preparation of puerarin composite skeleton sustained - release tablets, Journal of East China University of Science and Technology, 2011.2.(22):25. 
[9]Zhang fang, Study on Preparation Technology of Nimergoline Sustained Release Tablets, China Pharmaceuticals, 2010.19(15):41-42.

[10]Peng zhiping. Study on the preparation technology and in vivo release of Panax notoginseng saponins sustained - release tablets, Hubei University of Traditional Chinese Medicine, 2012.

[11]Huang haowu,Luo yuhong \&Liang feihua. Effect of preparation process of theophylline sustained - release tablets on release, China Medical Herald, 2010,7(7):42-44.

[12] National Pharmacopoeia Commission edits. Pharmacopoeia of the People 's Republic of China [M].China Medical Science Press, 2015:226. 